\title{
Potential Solutions to Water Scarcity in the Rural Watersheds of Nepal's Middle Mountains
}

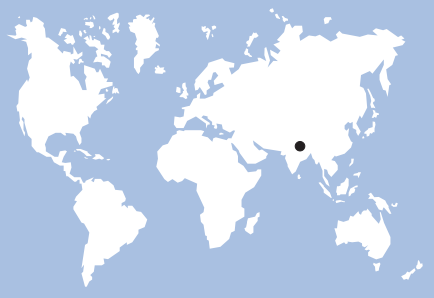

Water scarcity is a major issue in rural watersheds in the Middle Mountains of Nepal and in the entire Hindu Kush-Himalaya region. Dense population and heavy dependence on irrigated agriculture place immense pressure on available water resources, which have a distinct seasonality. New forms of management based on traditional and scientific knowledge must be introduced to solve problems of water supply, water demand, and water quality in these watersheds.

A related article in the Research section of this issue, Water: A Scarce Resource in Rural Watersheds of Nepal's Middle Mountains, by Juerg Merz et al, further explores the problem of water availability in Nepal. Ed.
FIGURE 1 A local woman with a project-financed water harvesting jar and a jar financed completely by her family. (Photo by Gopal Nakarmi)

\section{Scarcity and demand}

The global population has tripled in the last 100 years, whereas water use by humans has increased 6-fold. Major water shortages seem certain if these trends continue. With the aim of avoiding the risk of water deficiency, the World Water Council's World Water Vision report proposed a strategy that includes efforts to increase water availability and improve storage, reform water resources management institutions, appraise ecosystem functions, and increase transboundary cooperation.

To address these issues and the concerns of the residents of rural watersheds in the Middle Mountains of Nepal (see the paper by Merz et al in the Research section of this issue), new ways of managing available water resources must be adopted. A study conducted in 2 watersheds in Nepal-the Jhikhu Khola (JKW)

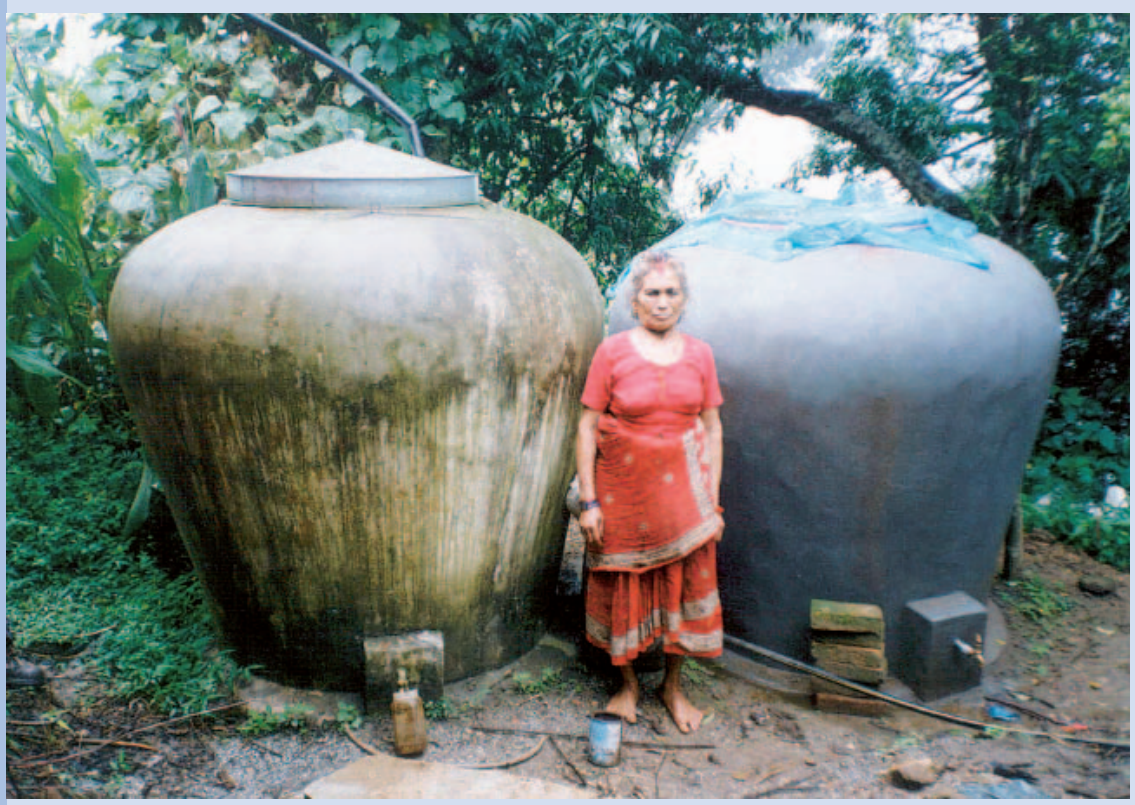

and the Yarsha Khola (YKW) - by the People and Resource Dynamics in Mountain Watersheds of the Hindu Kush-Himalayas Project (PARDYP), operated by the International Centre for Integrated Mountain Development (ICIMOD), revealed that:

1. Water resources are becoming increasingly scarce. Shortage of water for agricultural and domestic purposes during the dry months of the year is of particular concern. The main reasons for this are intensification of agriculture to meet the increasing demand for food from a rapidly growing population and development efforts to promote marketing of agricultural crops.

2. Issues related to water quality are of a growing concern among local residents in the area, primarily in the vicinity of settlements. Microbiological data show that fecal contamination is a problem throughout the watersheds. Intensified agriculture is adding to concerns about quality of water because shallow groundwater wells and surface water courses are contaminated by nitrate and phosphate at levels that pose a threat to health.

Management of water resources on this scale must address supply, demand, and quality from a social and technical point of view. The technical management options may be based on indigenous knowledge and traditional, often forgotten, methods or derived from scientific knowledge. The most important criterion, however, is that any solution to this problem has to be cheap, simple, and farmeroriented in order to be adopted by the population (Figure 1). 
With respect to the social organization of water resources management at the watershed scale in Nepal, the main area of concern is the degree of involvement of the government in the development and management of water supplies and in resolving conflicts between community-based and household-based water supplies. In Nepal, water supply has traditionally been organized at the community level. Supplies of irrigation water in the Middle Mountains are still organized largely by the farmers themselves, without the involvement of irrigation line agencies. An estimated $30 \%$ of the irrigated area is being developed by agencies, leaving the remaining $70 \%$ to farmers. Drinking water supply is still community-based to a large extent. However, more and more communities expect government or donor support for the maintenance of their systems.

Projects such as the Rural Water Supply and Sanitation Support Project (RWSSSP) of His Majesty's Government of Nepal and the Government of Finland focus on water supply at the household level. Similarly, Vision 21 of the Water Supply and Sanitation Collaborative Council is targeting households as the first planning and management level for environmental services, hoping that changes in households will lead to more cooperation in the neighborhood and the community. In this context, World Water Vision is calling for empowerment of communities and of both sexes.

In rural Nepal, water is still perceived to be a free public good. However, the development of infrastructure involves expenditure. This is true even for a simple gutter and drum used for water harvesting. The economic value of water has to be ascertained, and some payment is essential if water sustainability is to be achieved.

\section{Supply management}

The trend toward more efficient use of water seems to focus on the proper and environmentally sound use of water to the last drop, both for drinking and agricultural purposes. In the Middle Mountains of Nepal, water use has traditionally
FIGURE 2 Traditional water harvesting in the Middle Mountains of Nepal. (Photo by Gopal Nakarmi)

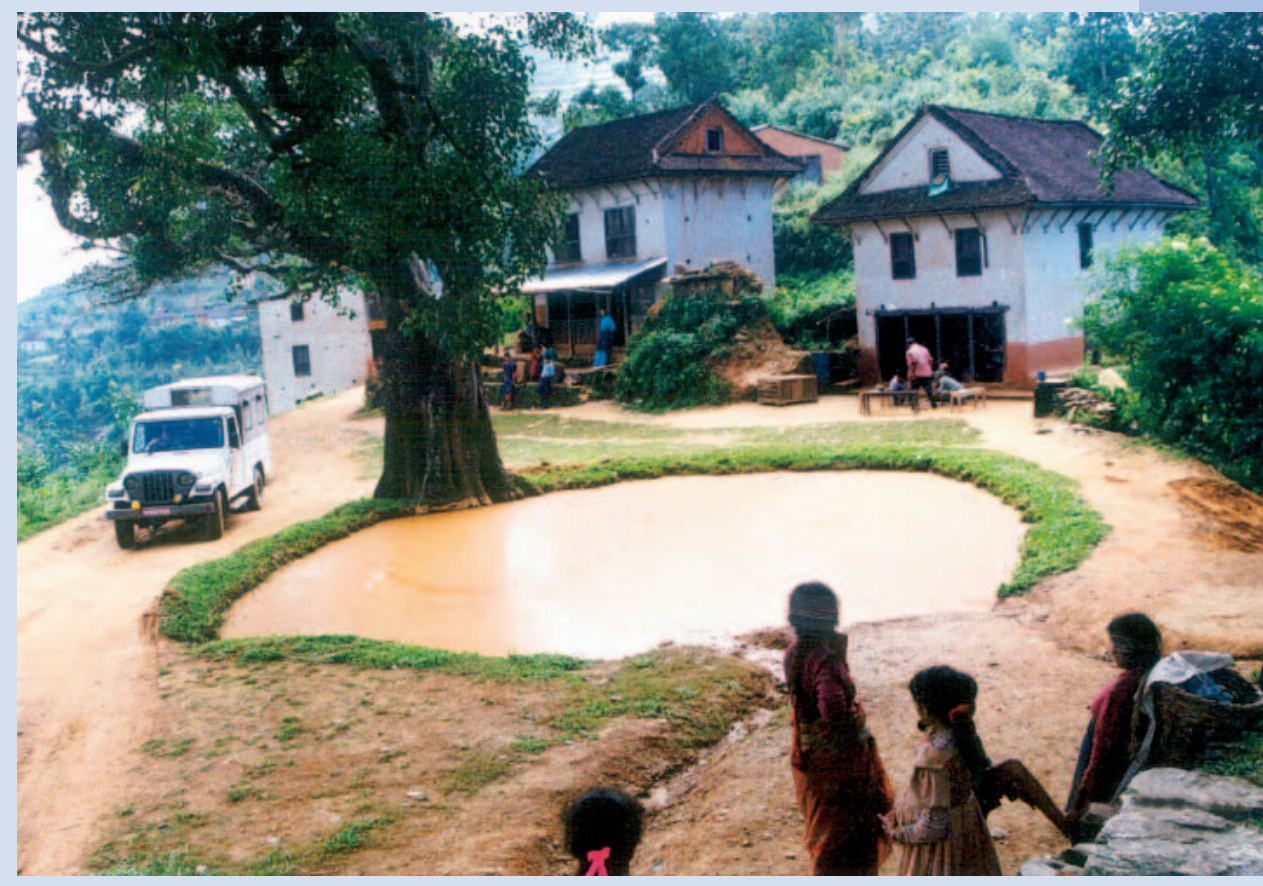

been restricted to springs and rivers. Most people in these areas still rely on natural springs and gravity-flow water supply systems, as shown by studies in JKW and YKW. Additional new water sources, such as groundwater, fog, and rainfall, need to be accessed to meet growing demands.

\section{Water harvesting}

Farmers in the Middle Mountains have traditionally managed ponds along ridges and on slopes for watering of animals (Figure 2). These ponds improved recharge and also helped to increase spring yields. Over time, however, many ponds disappeared because farmers did not maintain them and they silted up. Water supply from this form of surface runoff harvesting seems to be appropriate, both for improved recharge and smallscale irrigation. Storage facilities can be improved to enhance the availability of harvested surface water. PARDYP has carried out trials with underground cisterns to decrease evaporation losses from open water surfaces. However, the expenses involved in the setting up of this system are still too high for farmers to bear the initial cost.

Roof water harvesting for drinking has traditionally not been practiced in the 


\section{Alternative water application}

Traditionally, irrigation has been carried out largely by means of flood and furrow methods, depending on the crop. Vegetable crops are often irrigated by means of the bucket method, which involves a great deal of labor and time. Whereas irrigation of the staple crops depends greatly on the availability of water in the rivers to supply water to the irrigation systems, offseason vegetable production could be based on microirrigation. Depending on the crop and the location, sprinkler and drip irrigation systems appear to be appropriate alternatives. A number of different low-cost kits are provided by IDE. Compared with the traditional system of bucket irrigation, drip irrigation in small-scale cash crop farming has proven to be effective by reducing water application and by maintaining yield. Other methods such as bubble irrigation are used in the dry and cold zones of Pakistan.

\section{Water conservation}

Mulching with rice and wheat straw, as well as other on-farm and off-farm resources, has traditionally been practiced in Nepal for seedling production of different annual and perennial crops. In the Kathmandu Valley, rice husk is used for mulching in vegetable fields. In the hills, farmers use aromatic plants for mulching fruit trees. This labor-intensive practice, however, has been widely discarded in the region. Ginger and turmeric mulching is still widely practiced for production of annual crops. The Helvetas Sustainable Soil Management Project aims to promote traditional mulching practices with weeds and aromatic plants.

Besides these mulching materials, plastic film technology (PFT) has been used extensively for mulching throughout the world. China is a world leader in this technology; large areas under different crops are treated with PFT. The benefits of this technology are increased soil moisture retention, weed control, improvement of the temperature regime, promotion of seed germination, and accelerated growth leading to higher yields. One concern with PFT is the resulting plastic waste, which is harmful to the environment. Several ways of cop- ing with this issue and gaining economic benefits from it have been documented in China. In the context of Himalayan farming, it is suggested that this approach be used mainly for high-value cash crop production.

\section{Quality management}

In terms of quality management, there are 2 ways of fighting contamination: preventive and rehabilitative solutions. Water treatment, which is expensive, is considered rehabilitative but is usually a shortterm solution. Long-term or preventive measures are often more difficult to implement but are less expensive and lead to more appropriate and lasting solutions. With respect to water quality, both methods should be applied, as appropriate.

\section{Low-cost water treatment}

Microbiological contamination can be controlled by water treatment. Often, treatment involves high costs in terms of labor or money. This can be observed especially in the case of boiling, where fuelwood has to be collected or kerosene has to be purchased. Because of these costs, people refrain from boiling water. PARDYP has done some trials with lowcost water filters using locally available material. The latest tests using solar radiation to disinfect drinking water have been very promising. The Swiss Federal Institute for Environmental Science and Technology is promoting and disseminating a Solar Water Disinfection Process.

\section{Catchment and spring protection}

Two preventive measures can be taken to decrease the inflow of contaminants of different origin into the public water supply. Catchment protection focuses on preventing contaminants from being deposited in the recharge areas of springs and groundwater. This can be achieved by declaring these areas as protected zones where access to people and cattle is restricted. In the heavily populated areas in the Middle Mountains, the closure of recharge zones may be impracticable. However, careful management of these zones is possible with the involvement of 

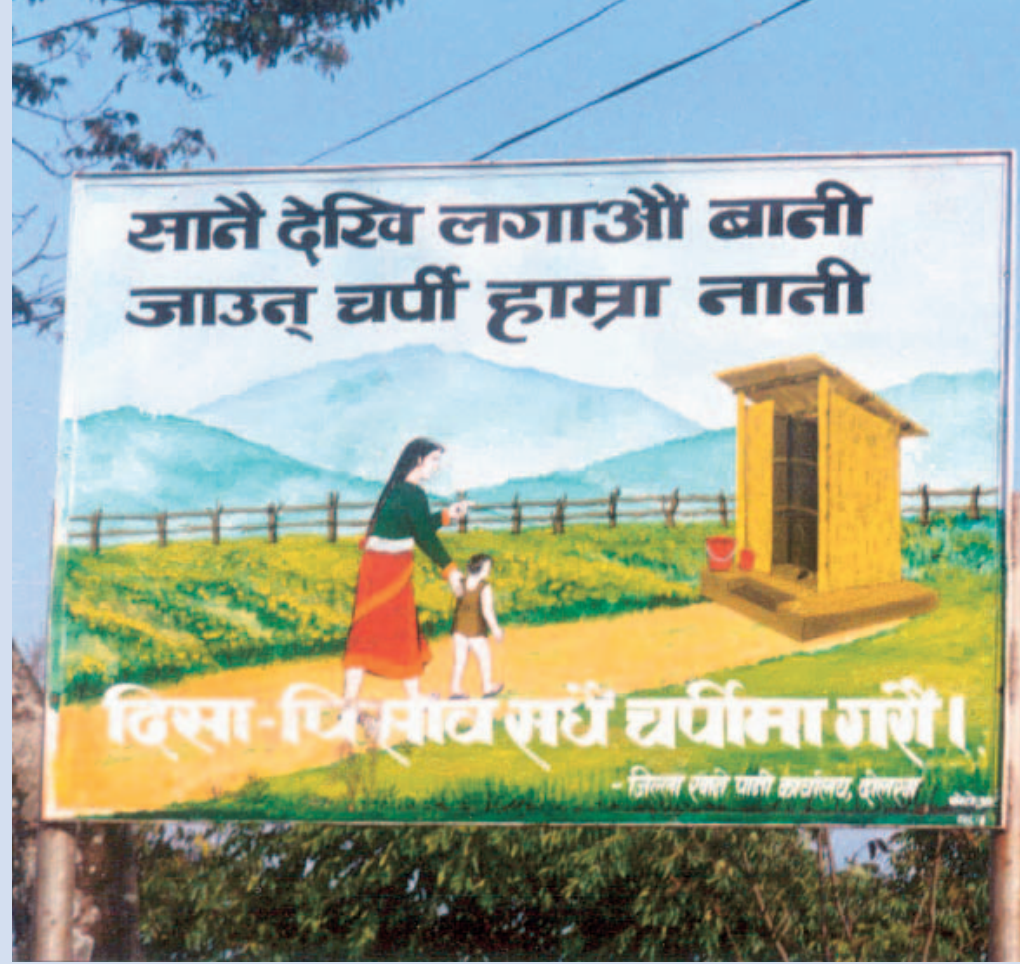

the community concerned and through creation of awareness among the people using the water (Figure 4).

Spring protection helps to decrease the inflow of contaminants at the supply
FIGURE 4 "Let's train our children to use the proper toilet." Awareness campaign for improved sanitation. (Photo by Juerg Merz)

point by preventing interaction between surface water and spring water. This can be achieved by diverting surface water around the spring box and by constructing and maintaining closed spring boxes. Measures to change sanitary conditions and practices around the wells and springs are a prerequisite.

\section{Conclusions}

Many residents of the Middle Mountains in the Hindu Kush-Himalaya face shortage of water for domestic and agricultural use. Improved supply, demand, and quality management of water resources must take into consideration the current situation, with active local participation and creation of awareness with respect to preventive and curative methods. Locally based organizations should be strengthened and fully involved in the discussion of water resources management. More studies need to be undertaken in this context to further support local groups in integrated water management.

\section{ACKNOWLEDGMENTS}

The authors would like to acknowledge financial support for the PARDYP project from the Swiss Agency for Development and Cooperation, the International Development Research Centre, and the International Centre for Integrated Mountain Development.

\section{AUTHORS}

\section{Juerg Merz}

Institute of Geography, Hydrology Group, University of Berne, Hallerstrasse 12, 3012 Berne, Switzerland. jmerz@icimod.org.np

Juerg Merz has been a research associate/hydrologist in the PARDYP project since 1998. In this capacity, he manages water and erosion studies in PARDYP Nepal and provides support to the PARDYP teams in China, India, and Pakistan.

\section{Rolf Weingartner}

Institute of Geography, Hydrology Group, University of Berne, Hallerstrasse 12, 3012 Berne, Switzerland. wein@giub.unibe.ch

Rolf Weingartner is the head of the Hydrology Group at the University of Berne and has served as an advisor to PARDYP on water and erosion activities since 1996.

Gopal Nakarmi

International Centre for Integrated Mountain Development, GPO Box 3226, Kathmandu, Nepal.

gnakarmi@icimod.org.np

Gopal Nakarmi is a water management specialist and is studying possible solutions to water scarcity and water quality problems in the 2 PARDYP Nepal watersheds.

\section{FURTHER READING}

Banskota M, Chalise SR, editors. 2000. Waters of Life: Perspectives of Water Harvesting in the HKH. Proceedings of the Regional Workshop on Local Water Harvesting for Mountain Households in the HKH, Kathmandu; 14-16 March 1999. Kathmandu, Nepal: International Centre for Integrated Mountain Development.

Hafeez S. 1998. Appropriate Farm Technologies for Cold and Dry Zones of the Hindu Kush-Himalayas. Kathmandu, Nepal: International Centre for Integrated Mountain Development.

Lu R. 1994. The Application of Plastic Film Technology in China. Kathmandu, Nepal: International Centre for Integrated Mountain Development.

Merz J, Nakarmi G, Shrestha S, Shrestha B, Shah PB, Weingartner R. 2002. Water and Erosion Studies of PARDYP Nepal: The Water Demand and Supply Survey. CD-ROM. Kathmandu, NEPAL: International Centre for Integrated Mountain Development.

Pacey A, Cullis A. 1986. Rainwater Harvesting: The Collection of Rainfall and Runoff in Rural Areas. London, UK: Intermediate Technology Publications. 